\title{
The Role of Anti-vascular Endothelial Growth Factor Agents in the Management of Retinopathy of Prematurity
}

\author{
Christopher D Conrady and M Elizabeth Hartnett \\ Department of Ophthalmology and Visual Sciences, John A Moran Eye Center, University of Utah, Utah, US
}

DOI: https://doi.org/10.17925/USOR.2017.10.01.57

etinopathy of prematurity is a vasoproliferative disease of preterm infants and has effects on infant vision and overall development. It is increasing worldwide with advances in perinatal care. In the following manuscript, we review the pathophysiology and possible treatments. We focused on anti-vascular endothelial growth factor (VEGF) agents and a few select other candidates.

\section{Keywords}

Retinopathy, prematurity, anti-VEGF, preterm, premature

Disclosure: Christopher D Conrady has nothing to disclose in realtion to this article. M Elizabeth Hartnett consulted for SanBio in the last year but has nothing to disclose in relation to this article. This study involves a review of the literature and did not involve any studies with human or animal subjects performed by any of the authors.

Acknowledgements: This work was supported in part by an unrestricted grant from Research to Prevent Blindness to the University of Utah's Department of Ophthalmology and Visual Sciences and National Eye Institute R01 grants EY015130 and EY017011 to MEH. M. Elizabeth Hartnett has received NIH grant support as principal investigator for the following: R01EY015130, R01EY017011, T35EY026511. The authors would also like to thank Lane Bennion for the medical renderings.

Authorship: All named authors meet the International Committee of Medical Journal Editors (ICMJE) criteria for authorship of this manuscript, take responsibility for the integrity of the work as a whole, and have given final approval to the version to be published.

open Access: This article is published under the Creative Commons Attribution Noncommercial License, which permits any noncommercial use, distribution, adaptation, and reproduction provided the original author(s) and source are given appropriate credit.

Received: November 2, 2016

Accepted: January 2, 2017

Citation: US Ophthalmic Review, 2017;10(1): 57-63

Corresponding Author: M Elizabeth Hartnett, Department of Ophthalmology and Visual Sciences, John A. Moran Eye Center, University of Utah, 65 Mario Capecchi Dr., SLC, UT, 84108, US. E: me.hartnett@hsc.utah.edu
Retinopathy of prematurity (ROP) is a vasoproliferative disease of preterm infants that continues to be a major cause of preventable blindness worldwide despite concerted efforts to reduce its frequency. In developed countries, advances in perinatal care, a reduction in mortality rates of preterm infants, and increased surveillance for ROP has had unintended consequences and has resulted in nearly a 10-fold increase in ROP cases worldwide in the past 20 years. ${ }^{2-4}$ In the United States, nearly $16 \%$ of premature infants hospitalized for more than 28 days develop ROP, and ROP is responsible for 6-20\% of childhood blindness in the country. ${ }^{1,56}$ As a result, the National Eye Institute estimates that approximately 14,000 neonates a year in the United States develop ROP, and of these approximately 400-600 become completely blind. In 2010, a meta-analysis estimated 184,700 new cases of ROP worldwide of which 20,000 babies became blind, and an additional 12,300 developed mild to moderate visual impairment due to the disease. ${ }^{8}$

Besides the obvious toll on patients and families, blindness acquired in infancy has a significant economic impact as well. In Peru, early treatment of ROP to prevent neonatal blindness resulted in nearly a $\$ 200,000$ cost savings to the society (in US dollars). ${ }^{9}$ The authors of the study further estimated that this would result in $\$ 516$ million cost savings across a generation in Peru. ${ }^{9}$ This finding has been reiterated in the developed world as well. ${ }^{10}$ Consequently, ROP is a leading cause of childhood blindness worldwide with a significant economic impact. ${ }^{11}$

Many attempts have been made to quell ROP due to its consequences both for the patient and community. Oxygen monitoring and regulation to reduce high oxygenation has had a noticeable effect on reducing the risk of developing ROP in preterm infants. ${ }^{12}$ Furthermore, teleretinal imaging has shown promise in detecting ROP of any stage, with sensitivities of 76-97\% and specificities of 89-100\% in a meta-analysis. ${ }^{13}$ While this will presumably make ROP classification more accessible to areas of the world lacking trained specialists, it is unclear what impact it will have on the disease treatment and outcomes. One burden is the concern that there are insufficient numbers of trained ophthalmologists to treat infants with severe ROP. ${ }^{14}$ Despite these recent advances in surveillance and treatment, the disease remains an important cause of childhood blindness worldwide and likely will be for the foreseeable future.

\section{Role of vascular endothelial growth factor in angiogenesis}

vascular endothelial growth factor (VEGF) is an important growth factor in angiogenesis and lymphangiogensis that promotes vessel sprouting, endothelial cell growth, survival, and homeostasis. ${ }^{15,16}$ VEGF consists of a family of six subtypes that signal through activation of three distinct receptors that have been discussed extensively elsewhere (Figure 1)..$^{17-19}$ Dysregulation of VEGF-A and its activation of VEGF receptor (VEGFR)-1 and -2 are believed to be an underlying mechanism in ROP, and for simplicity, VEGF-A will subsequently be referred to as VEGF throughout 
Figure 1: Schematic of vascular endothelial growth factor signaling

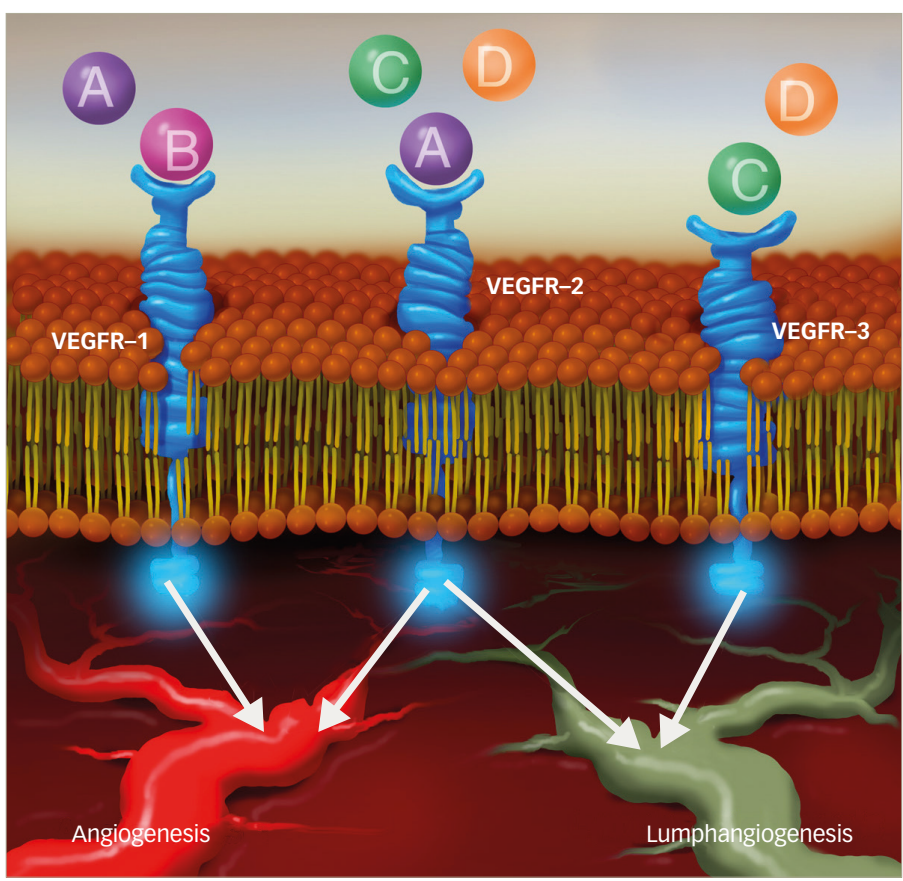

Vascular endothelial growth factor (VEGF) has multiple subtypes (A-D) and three receptors (VEGFR1-3) facilitating angiogenesis and/or lymphangiogenesis.

this manuscript. ${ }^{20}$ VEGF production is highly regulated by local host oxygen concentrations and tissue demands. VEGF is regulated by hypoxiainducible factor-1, a transcription factor that accumulates in hypoxic conditions due to a concurrent decrease in proteolytic degradation. ${ }^{21-24}$ This has been clearly shown to occur both temporally as well spatially in ischemic mouse retinas. ${ }^{25}$ Thus, VEGF is highly regulated by oxygen conditions at the cellular and molecular level in diseased tissue.

However, the role of VEGF in endothelial cell survival requires other factors to induce its full angiogenic effect. A non-oxygen-regulated growth factor, insulin-like growth factor (IGF)-1, is another such factor that is able to activate Akt (Protein Kinase B). ${ }^{26-28} \mathrm{Akt}$ is a serine/threonine kinase required to promote cell survival by way of phosphoinositide 3-kinase (PI3K) and subsequent activation of cell survival signals and, thus, regulate VEGF signaling to change physiologic to pathologic angiogenesis. ${ }^{29-32}$ In fact, low levels of IGF-1 suppress VEGF-survival signaling, and altered concentrations of IGF-1 result in abnormal vascularization of the mouse and presumably human retina in diseases such as ROP. ${ }^{30,33-35}$ Consequently, the relative concentrations of VEGF and IGF-1 are some of many defining components of the two "phases" discussed below. ${ }^{36}$ Unfortunately, neither VEGF nor IGF-1 serum concentrations has been shown to have a predictive role in identifying neonates that will develop progressive ROP. ${ }^{37}$

\section{Pathophysiology of retinopathy of prematurity}

ROP is classified by zone, stage, and the presence of plus disease. ${ }^{38,39}$ Experimentally, ROP has been studied using models of oxygen-induced retinopathy $(\mathrm{OIR}) .^{40}$ The initial OIR studies were done in the cat in the 1950's when oxygen levels were not regulated or monitored and when premature infants were larger and of older gestational ages. From those
Figure 2: Stages and zones of retinopathy of prematurity

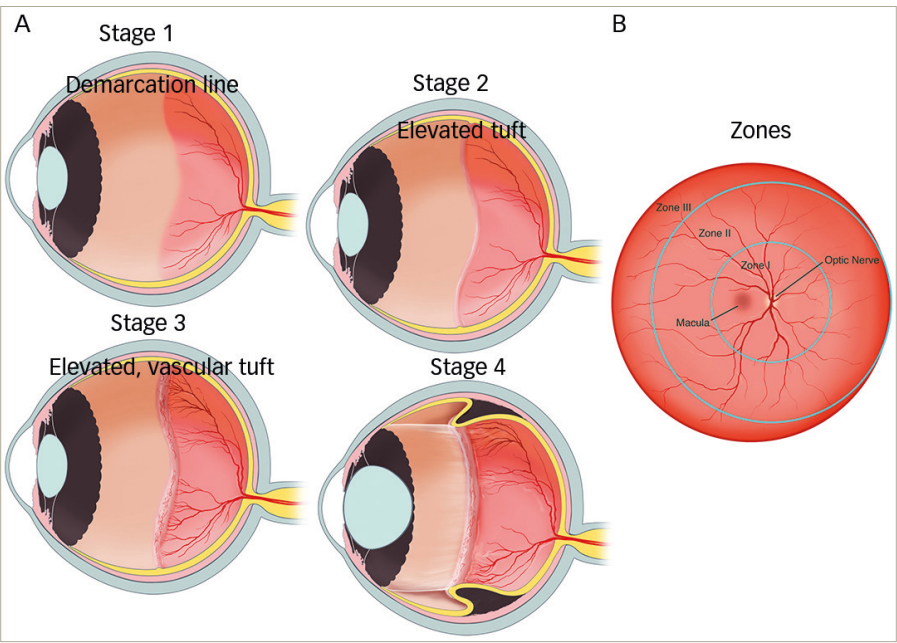

A. Retinopathy of prematurity (ROP) nomenclature is defined by stages 1 (demarcation line), 2 (elevated tuft of tissue), 3 (fibrovascular growth into the vitreous), 4 (partial retinal detachment), and 5 (total retinal detachment with funnel - not shown in the figure). $B$. Zones are defined by location from the optic nerve. Vascular dilatation and tortuosity (plus disease) is based on the original International Classification system as the final component of ROP nomenclature.

early studies, two phases were used to describe OIR: an early hyperoxiainduced vaso-obliterative phase (Phase I) followed by a later hypoxiainduced vaso-proliferative phase (Phase II). The phases are helpful to model discrete time points in studying the pathogenesis of OIR, but the phases rarely translate to changes in the individual human preterm infant retina. Also, use of high oxygen is avoided in the US and countries with the technology to regulate and monitor oxygen. OIR models that are representative of human ROP are used to understand pathophysiology. ${ }^{40,41}$

\section{Staging of retinopathy of prematurity}

In the mid-1980s, the International Classification of Retinopathy of Prematurity was published to guide diagnosis and treatment of ROP and was then updated in the early 2000s as more information on ROP became available (Figure 2). ${ }^{38,39,42}$ This classification system has since become the basis of multiple, multicenter, randomized controlled trials as it standardized ROP grading. These subsequent trials have since defined prevention, surveillance, and treatment of ROP. The nomenclature was defined by zones and stages of location, extent of stage and the presence of vascular dilatation and tortuosity (plus disease) in the International Classification system. ${ }^{42}$ Additionally, the Early Treatment for Retinopathy of Prematurity (ET-ROP) study, has changed the nomenclature of severe ROP to type 1 versus type 2 ROP from analysis of retrospective data from the ET-ROP study. ${ }^{43}$ Type 1 ROP includes eyes with zone I and any stage ROP with plus disease, zone I stage 3 without plus disease, or zone || with stage 2 or 3 and plus disease. ${ }^{44}$ Type 1 ROP is considered high-risk and is recommended for treatment, whereas type II is usually closely monitored. ${ }^{11}$ Subsequent follow up and treatment are then determined based on ophthalmic findings and infant age. ${ }^{11}$

\section{Complications of retinopathy of prematurity}

There are many well-documented complications of ROP. They include tractional retinal detachment from fibrovascular proliferation, and subsequent vision and visual field loss, glaucoma, high myopia, retinal folds, tears and detachments, and macular dragging. ${ }^{45}$ 


\section{Current standard of care and pitfalls}

The current standard of care for Type 1 ROP is treatment of the avascular, hypoxic peripheral retina with laser, preferable to cryotherapy.43,44 This treatment is believed to treat hypoxic cells that upregulated VEGF and other angiogenic factors and/or indirectly to reduce the angiogenic stimulus to hypoxic retina and downregulate angiogenic signaling in order to reduce abnormal vessel growth, and later fibrovascular retinal detachment and blindness. ${ }^{44,46-48}$ The ET-ROP study showed that laser performed for high risk prethreshold disease ( $\geq 15 \%$ risk of progression to an unfavorable outcome from previously defined modeling ${ }^{49}$ ) resulted in a reduction of unfavorable visual acuity outcomes from $19.8 \%$ to $14.3 \%$ and unfavorable anatomic outcomes from $15.6 \%$ to $9.0 \%$ (Table 1).44,50,51 However, if treatment is initiated later, or is inefficient and/or incomplete, therapeutic results can be poor in some cases because of continued vasoproliferation and fibrovascular changes. Even with successful treatment and preserved retinal attachment, visual outcomes can be poorer than desired. The ET-ROP study reported that visual acuity was $20 / 40$ or better in only $34.6 \%$ that underwent early treatment 6 years later. ${ }^{52-54}$ Possible causes of poor vision $(\leq 20 / 200)$ despite a normal fundus include cortical blindness, other anterior and posterior visual pathway diseases that require further study, and neurovascular dysfunction at the retinal level..$^{55-57}$

Unfortunately, while effective if performed appropriately, laser or, less frequently cryotherapy, requires proficiency in indirect ophthalmoscopy and scleral depression in neonates and is time intensive requiring at least 2 hours per laser treatment. ${ }^{58}$ Worldwide, there is currently a shortage of adequately trained ophthalmologists to diagnose and treat ROP.59 Teleretinal imaging is being used to diagnose and stage ROP in efforts to address shortage of ophthalmologists in certain areas..$^{60}$ Additionally, some postnatal weight-gain algorithms have been developed and tested to identify infants at risk to develop ROP or severe ROP. However, these efforts will have no effect on the lack of available ophthalmologists for treatment, ${ }^{1-63}$ and studies are still evaluating its widespread use. ${ }^{64}$ However, it remains to be seen if efforts to address screening burden will also address the lack of qualified ophthalmologists to provide appropriate treatment. 2.59

In some cases, despite early laser therapy or in those infants in whom late recognition of the disease occurred, ROP can progress to retinal detachments and other complications. Thus, early recognition and treatment is paramount to avoid late complications and maintain vision. Scleral buckles and vitrectomies are used to treat retinal detachment. ${ }^{45}$ Other treatment modalities are being tested to combat ROP and the longterm consequences.

\section{Anti-vascular endothelial growth factor}

The development of anti-VEGF agents has led to their widespread use in treating diabetic macular edema, macular edema from vein occlusions, proliferative diabetic retinopathy, neovascular glaucoma, neovascular age-related macular degeneration, and choroidal neovascular membranes. ${ }^{65,66}$ There are currently four anti-VEGF agents on the market delivered as intravitreal injections: pegaptanib, ranibizumab, aflibercept, and bevacizumab. While bevacizumab is not currently approved for intravitreal use, its off label use has been well tolerated and quite effective in treating the entities described above for over 10 years. ${ }^{67-69}$ Pegaptanib is a selective inhibitor of the VEGF165 isoform, while ranibizumab, a monoclonal antibody fragment, aflibercept, an engineered fusion protein fused to the Fc portion of human immunoglobulin G (IgG)1,
Table 1: Landmark, randomized control trials in retinopathy of prematurity

\begin{tabular}{|c|c|}
\hline Study & Significant findings \\
\hline SUPPORT 126 & $\begin{array}{l}\text { Oxygen saturation targets of } 85-89 \% \text { compared to } 91-95 \% \text { reduced } \\
\text { rates of ROP but increased rates of mortality }\end{array}$ \\
\hline BOOST $\|^{127}$ & Similar to those found in the SUPPORT study \\
\hline $\mathrm{COT}^{128}$ & $\begin{array}{l}\text { While this study had different enrollment criteria, this study found } \\
\text { no difference in rates of ROP and mortality with oxygen }\end{array}$ \\
\hline \multirow[t]{2}{*}{ CRYO-ROP51 } & 1. Defined threshold disease \\
\hline & $\begin{array}{l}\text { 2. Showed treating threshold disease reduced unfavorable } \\
\text { structural outcomes from } 47 \% \text { to } 25 \%\end{array}$ \\
\hline $\begin{array}{l}\text { Laser Study } \\
\text { Group }^{129}\end{array}$ & $\begin{array}{l}\text { Laser photocoagulation comparable to cryotherapy in outcomes } \\
\text { with less effect on refractive error }\end{array}$ \\
\hline \multirow[t]{2}{*}{ ET-ROP $^{44}$} & $\begin{array}{l}\text { 1. Early treatment of high risk, prethreshold disease reduced } \\
\text { unfavorable structural outcomes from } 15.6 \% \text { to } 9.1 \%\end{array}$ \\
\hline & 2. Defined type I versus type II ROP \\
\hline BEAT-ROP 76 & $\begin{array}{l}\text { Treatment of stage } 3+\text { zone } 1 \text { disease with bevacizumab showed } \\
\text { significant reduction in recurrence compared to conventional laser }\end{array}$ \\
\hline
\end{tabular}

There have been many landmark trials in retinopathy of prematurity (ROP). The Respiratory outcomes of the Surfactant Positive Pressure and Oximetry Randomized Trial (SUPPORT) and the Benefits of Oxygen Saturation Targeting (BOOST) II trials showed that lower oxygen targets resulted in lower rates of ROP. The Canadian Oxygen Trial (COT) had a different enrollment criteria but found no difference in ROP rates and mortality due to oxygen saturation goals. The cryotherapy for (CRYO)-ROP trial defined threshold disease $(50 \%$ risk of poor outcomes) and showed that treating threshold disease with cryotherapy resulted in reducing unfavorable outcomes. The Laser ROP Study Group showed that laser photocoagulation was equally efficacious to cryotherapy but with a reduced effect on inducing high myopia. The Early Treatment of (ET)-ROP defined high risk, prethreshold disease ( $15 \%$ risk of poor outcome) and that if treated, reduced ROP-related complications even further than the CRYO-ROP study found. The Bevacizumab Eliminates the Angiogenic Threat of (BEAT)-ROP study then identified a role of anti-VEGF agents in ROP.

and bevacizumab, a monoclonal antibody, are all non-selective VEGF

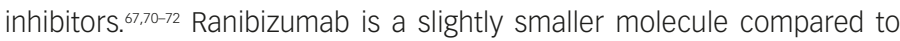
aflibercept and bevacizumab, while aflibercept has the broadest spectrum of activity. ${ }^{73}$ Due to their ease of administration and mechanism of action, some of these agents have been proposed as potential therapeutic agents that could avert an emerging crisis due to a shortage of trained ophthalmologists available to treat ROP worldwide. In addition, many of the preclinical studies done for diabetic eye disease and age-related macular degeneration used models of OIR to test the effect of anti-VEGF treatments. Although OIR models do not completely translate to human ROP, some similarities in stresses and outcomes led to a movement from OIR to ROP. Using the representative rat model, it was found that inhibition of VEGFR2 signaling reduced neovascularization but did not inhibit physiologic retinal vascularization in an incompletely understood process. This suggested that inhibiting, but not completely abolishing VEGF signaling, would not only be safe for retinal vascular development but would also reduce vasoproliferation in ROP. ${ }^{26-28,74}$ This hypothesis was corroborated in part by an early, promising, interventional cases series and another randomized trial that have since paved the way for larger interventional studies. ${ }^{75,76}$

Several studies evaluating the efficacy of anti-VEGF agents in ROP have shown promise but lack longitudinal, extended follow up (Table 2). Furthermore, most of the studies have been relatively small. One such study that included 13 infants found that there was no difference in visual acuity and refractive error in those preterm infants treated with intravitreal bevacizumab or laser for type 1 ROP in zone I or $1 . .^{77}$ This was also reported 
Table 2: Pros and cons of intravitreal injections for retinopathy of prematurity

\begin{tabular}{|l|l|}
\hline Pros & Cons \\
\hline Ease of administration & Possible systemic side effects \\
\hline Lower risk of high myopia & Higher risk of recurrence of ROP \\
\hline $\begin{array}{l}\text { Chance of revascularization of } \\
\text { peripheral retina }\end{array}$ & Unknown long-term consequences \\
\hline
\end{tabular}

There are several notable pros for intravitreal injections of anti-VEGF agents in the treatment of retinopathy of prematurity (ROP). They include ease of administration, lower risk of myopia than laser, and a chance of allowing revascularization of the peripheral retinal. However, there are several potential downsides to ant-VEGF agents in preterm infants such as the unknown long-term consequences, potential systemic side effects, and a higher rate of recurrence of ROP than laser.

in a study of 26 patients with stage 3 ROP treated with bevacizumab in whom involution of neovascularization, flattening of demarcation lines, and growth of differentiated vessels into capillary-devoid areas was noted. ${ }^{78}$ In a larger study of 152 eyes with stage 3+ ROP in zone I or II, intravitreal pegaptanib combined with diode laser photocoagulation outperformed laser therapy and cryotherapy in reducing rates of recurrence of stage 3 disease. This combination therapy also led to faster resolution of neovascularization following initial treatment.79 Additionally, a more recent retrospective study showed that bevacizumab with or without zone I sparing laser reduced unfavorable outcomes (i.e., retinal folds, disc dragging, retinal detachments, early refractive errors, and retrolental tissue obscuring the view of the posterior pole) from $22.7 \%$ to $0 \%$ as compared to laser alone. ${ }^{80}$ The Bevacizumab Eliminates the Angiogenic Threat of (BEAT)-ROP was a randomized, multicenter trial that evaluated the efficacy of bevacizumab in neonates with stage $3+$ in zone I or II and found similar results for zone I to those seen with pegaptanib. ${ }^{76}$ However, bevacizumab did not show a significant treatment effect for zone II disease in this study. ${ }^{76}$ Additionally, a randomized, controlled clinical trial has shown that those infants treated with bevacizumab had statistically significant lower rates of very high myopia and spherical equivalent refractions compared to those treated with laser. ${ }^{81}$ Specifically, infants with zone I disease treated with bevacizumab had mean spherical equivalent refractions of -1.51 diopters (D) versus those treated with laser who had $-8.44 \mathrm{D}$. This significant trend continued into posterior zone II (-0.58 D versus $-5.83 \mathrm{D})$. Lower rates of very high myopia ( $\geq-8.00 \mathrm{D}$ ) in infants with ROP in zone I and II was also reported following bevacizumab injection versus laser treatment (3.8\% versus $51.4 \%$, $1.7 \%$ versus $36.4 \%$, respectively). ${ }^{81}$ Other retrospective reports have shown similar results. ${ }^{82-84}$ Furthermore, a recent Cochrane meta-analysis that reported reduced myopia and retinal detachment with anti-VEGF agents, emphasized that the quality of evidence did not allow authors to fully rule out bias. The Cochrane review concluded that due to insufficient data and an unbeknownst systemic safety profile that strong conclusions could not be made favoring routine use of anti-VEGF agents. ${ }^{85}$ While the BEAT-ROP trial has shown promising results of anti-VEGF therapy when compared to peripheral laser photocoagulation for stage 3+ disease, there are still many significant questions that must be answered before widespread use is adapted into clinical practice. ${ }^{76}$ The current recommendations of the American Academy of Pediatrics include considering bevacizumab for zone I, stage 3 with plus ROP and treatment of type 1 ROP with laser. ${ }^{11}$

The role of anti-VEGF agents in treatment of ROP has insufficient evidence regarding the agent, dose, treatment regiment, efficacy versus laser and safety, to yet recommend widespread acceptance to preterm neonates who are medically fragile. While there have been no long-term safety studies in premature infants who are still undergoing development, there have been several studies addressing safety in adults undergoing repeated administration of anti-VEGF. A recent meta-analysis evaluated long-term safety in adults with diabetic macular edema and included a total of 1328 patients from four separate studies. The authors concluded that those patients who received the highest exposure of ranibizumab, monthly injections for 2 years, as compared to sham or laser treatment had an increased risk of death, cerebrovascular events, and vascular death (odds ratio of $2.98,2.33$, and 2.51 respectively). ${ }^{86}$ This was in contrast to an older Cochrane review published in 2014 that found no difference in systemic adverse events in those treated with anti-VEGF agents on an as-needed basis versus those who had not. ${ }^{87}$ These disparate results, we postulate, could be due to more stringent inclusion criteria of the first study requiring imposed monthly injections for two years, while the latter included studies with far fewer treatments. Thus, there are safety concerns in premature infants but to what effect remains unseen. Even though neonates are not usually more than one dose, there is evidence that current anti-VEGF doses administered to infants causes a greater effect than in adult, and may have adverse effects on organ systems and neural cognition in developing preterm infants. ${ }^{88}$

In premature infants, there is very little information on the safety profile of anti-VEGF therapy. Experimental evidence supports that VEGF is an important survival factor for glial and neural cells..$^{89,90}$ In neonatal mice, anti-mouse VEGF 164 antibody has been shown to reduce brown fat."1 Thus, experimental evidence would suggest both local and systemic effects from treatment with potential long-term consequences. In infants, intravitreal bevacizumab reduces systemic VEGF concentrations for up to 2 months due to systemic leakage from the vitreous. ${ }^{91-93}$ In a small study including 11 infants followed weekly for a month, ranibizumab only suppressed plasma VEGF for up to 1 week but unfortunately had much higher rates of ROP recurrence than bevacizumab. ${ }^{94-96}$ This systemic absorption and pronounced VEGF neutralization raises concerns about effects on developing neural and vascular beds in the premature infant. The Canadian Neonatal Network study found that infants treated with bevacizumab had higher odds of severe neurodevelopmental disabilities compared to those infants treated with laser. ${ }^{97}$ The study was retrospective, relatively small in size and was not randomized, in that infants treated with bevacizumab had more medical issues and potentially prone to neurocognitive delays. Nonetheless, the study raises important safety concerns of anti-VEGF therapy.

There are well-documented immediate complications to anti-VEGF therapy in some neonates. Reports of anti-VEGF complications include peripheral retinal abnormalities (i.e., large, avascular areas, abnormal branching vessels, and/or shunt vessels) or posterior pole anomalies (i.e., hyperfluorescent lesions and absence of foveal avascular zones) compared to those treated with laser, as seen by fluorescein angiography. ${ }^{98}$ While this study was limited by short follow up time of 9 months and only 13 infants being enrolled in the study, the findings raise concerns for lasting negative architectural effects of anti-VEGF treatment. ${ }^{98}$ Additionally, infants treated with bevacizumab or ranibizumab have been reported to have recurrence of ROP between 4 and 35 weeks after initial treatment.95,96,99 Another small retrospective study that included 58 eyes noted that those infants requiring earlier bevacizumab treatment or had lower initial birth weights required significantly higher 
rates of rescue treatment. ${ }^{100}$ In the rat 50/10 OIR model, it was shown that inhibition of VEGF bioactivity using a neutralizing antibody led to later intravitreal neovascularization in part associated with activation of other angiogenic pathways. ${ }^{101}$ The late reactivation in infants also makes extended follow up a necessity compared to laser therapy in a world where providers are already difficult to find. Additionally, the risks of complications directly associated with the injection, such as endophthalmitis, are rare but real. ${ }^{102}$

\section{Recombinant IGF-1 supplementation}

As previously mentioned, the interplay between VEGF and IGF-1 may be a driving force in the development of ROP; lower serum levels of IGF1 are seen in preterm babies that develop ROP. ${ }^{35,03}$ Moreover, serum IGF-1 levels are known to precipitously drop following preterm delivery due to the loss of interaction between the fetus and mother in utero. ${ }^{104}$ Thus, groups have proposed supplementing preterm infants with IGF-1 to in utero levels of infants of similar developmental ages $(\leq 33 \mu / L$ at 33 weeks postmenstrual age raises risk for any preterm morbidity 2.2 fold $^{35}$ ) to promote physiologic retinal vascularization and reduce hypoxia resulting from large areas of avascular retina, which is a risk for the development of ROP. ${ }^{35} \mathrm{~A}$ recent phase II clinical trial evaluated continuous infusion of IGF-1 required to maintain serum IGF-1 levels (clinical trial NCT01096784) and did not reach its primary outcome measure of reduced severe ROP, but had important reductions in secondary outcomes such as bronchopulmonary dysplasia and severe intraventricular hemorrhage. A 2-year interim study is planned through 2018 (Section D, NCT01096784; PEDAL, NCT02386839). Several smaller studies had already shown safety of the proposed treatment. ${ }^{105,106}$ Furthermore, IGF-1 knockout mice have impaired retinal vessel growth and treating mice with OIR, which simulates ROP, with recombinant IGF-1 results in a decrease in retinopathy and faster overall developmental maturation. ${ }^{30,107}$ Unfortunately, this recent randomized trial with recombinant human IGF-1 did not meet its endpoint of reducing rates of ROP; however, this drug may become important in reducing other prematurity-related health problems.

\section{Additional benefit from anti-oxidants such as D-Penicillamine, long chain fatty acids, or vitamin E in preventing ROP}

Recent experimental evidence has shown a role of free radicals inducing retinopathy through NADPH oxidase-dependent reactive oxygen species generation and has been speculated to be a contributor to the initial development of angiogenesis and ROP. ${ }^{108-113}$ Several small clinical studies have shown some efficacy of reducing the frequency of ROP by neutralizing oxidative compounds. Once such agent, D-Penicillamine, is a potent anti-oxidant that has been shown in a small, non-randomized study to reduce ROP development in preterm infants who enterally received a 14-day course of the medication. Of note, there was no associated systemic toxicity associated with the treatment.?.114 While the mechanism is unclear, D-Penicillamine is thought to chelate pro-oxidant heavy metals thereby reducing free radical activity and subsequent retinal injury required to initiate ROP. ${ }^{7.115}$ Unfortunately, a more recent Cochrane meta-analysis found no benefit to D-Penicillamine administration to prevent ROP on currently available evidence. ${ }^{116}$ This will likely end any future role of the drug in ROP prevention.

Omega-3 and -6 polyunsaturated fatty acids are long chain fatty acids that must be consumed in diets and are transferred from mother to fetus during the third trimester. They are the predominant fatty acid in brain gray matter and retinal membranes. ${ }^{104}$ These fatty acids have been shown to prevent photoreceptor apoptosis in vitro in response to oxidative stress and are known potent anti-oxidants. ${ }^{11-119}$ In mouse pups with induced oxidative retinopathy whose mothers were fed with Iong chain fatty acids, these mice were shown to have revascularization of avascular retina and reduced neovascularization due to lower concentrations of inflammatory mediators. This resulted in attenuated endothelial cell activation. ${ }^{120,121}$ In a small, observation study from Poland, preterm neonates requiring total parenteral nutrition were given either a diet with fish-emulsion (contains docosahexaenoic acid) additive versus control.122 In the group receiving the fish extract, there was less need for laser therapy and more infants had increased rates of spontaneous regression of ROP. ${ }^{122}$ Regrettably, this did not result in better visual outcomes (i.e., improved visual acuity and visual evoked potentials). ${ }^{122}$ These results were subsequently confirmed with a small, randomized control trial from the same group. ${ }^{123}$ Thus, it is likely that supplementation with long chain fatty acids will have some role in reducing the risk of developing ROP in preterm, very low birth weight infants but its exact role is still unclear at this time.

Vitamin E is a free radical scavenger, and due to the aforementioned role of antioxidants in reducing ROP risk, has been tested in several large studies. While high doses of vitamin $\mathrm{E}$ have shown to decrease ROP risk and blindness, there are risks including of sepsis. ${ }^{24}$ Therefore, current Cochrane meta-analyses compiling 26 randomized clinical trials recommended against high dose vitamin $\mathrm{E}$ supplementation due to lack of supportive evidence and risks associated with it. ${ }^{125}$ Therefore, vitamin E is not recommended for preventing ROP.

\section{Conclusion}

In conclusion, the role of anti-VEGF therapy in ROP treatment is controversial but from available evidence, it appears that regulation of the VEGF signaling pathways may have a place in facilitating physiologic angiogenesis and inhibiting pathologic angiogenesis. However, there are safety concerns that have not been fully evaluated in the small-scale studies done to date. In infants being evaluated for anti-VEGF therapy, informed consent is paramount as long-term effects are unknown. Currently, the American Academy of Pediatrics (AAP) and American Academy of Ophthalmology (AAO) recommends laser for type 1 ROP and consideration of the use of anti-VEGF agents in infants with zone I ROP, with stage 3 and plus disease. ${ }^{11}$ Currently clinical trials (NCT02390531 and NCT02375971) are testing the effect of several doses and of anti-VEGF versus laser. The evidence from these randomized controlled studies will hopefully provide greater insight into safe and effective treatments for ROP. However, future treatments may need to target pathways involved in pathologic vascular signaling without adversely affecting neural development. $\square$ 
1. Gilbert C, Rahi J, Eckstein M, et al., Retinopathy of prematurity in middle-income countries, Lancet, 1997;350:12-4.

2. Painter SL, Wilkinson AR, Desai P, et al., Incidence and treatment of retinopathy of prematurity in England between 1990 and 2011 database study, Br J Ophthalmol, 2015;99:807-11.

3. Group BIUKC, Group BIAC, Group BINZC, et al., Oxygen saturation and outcomes in preterm infants, N Eng/J Med, 2013;368:2094-104

4. Network SSGotEKSNNR, Carlo WA, Finer NN, et al., Target ranges of oxygen saturation in extremely preterm infants, N Eng/ J Med, 2010;362:1959-69.

5. Lad EM, Hernandez-Boussard T, Morton JM, Moshfeghi DM, Incidence of retinopathy of prematurity in the United States: 1997 through 2005, Am J Ophthalmol, 2009;148:451-8.

6. Steinkuller PG, Du L, Gilbert C, et al., Childhood blindness, J AAPOS, 1999;3:26-32.

7. Christensen RD, Alder SC, Richards SC, et al., D-Penicillamine administration and the incidence of retinopathy of prematurity, J Perinatol, 2007;27:103-11

8. Blencowe H, Lawn JE, Vazquez T, et al., Preterm-associated visual impairment and estimates of retinopathy of prematurity at regional and global levels for 2010, Pediatr Res, 2013;74 Suppl 1:35-49.

9. Dave HB, Gordillo L, Yang Z, et al., The societal burden of blindness secondary to retinopathy of prematurity in Lima, Peru, Am J Ophthalmol, 2012;154:750-5.

10. Kamholz KL, Cole CH, Gray JE, Zupancic JA, Cost-effectiveness of early treatment for retinopathy of prematurity, Pediatrics, 2009;123:262-9.

11. Fierson WM, American Academy of Pediatrics Section on $\mathrm{O}$, American Academy of $\mathrm{O}$, et al. Screening examination of premature infants for retinopathy of prematurity, Pediatrics, 2013;131:189-95

12. Zepeda-Romero LC, Lundgren P, Gutierrez-Padilla JA, et al., Oxygen Monitoring Reduces the Risk for Retinopathy of Prematurity in a Mexican Population, Neonatology, 2016;110:135-40

13. Richter GM, Williams SL, Starren J, et al., Telemedicine for retinopathy of prematurity diagnosis: evaluation and challenges, Surv Ophthalmol, 2009;54:671-85.

14. Varughese S, Gilbert C, Pieper C, Cook C, Retinopathy of prematurity in South Africa: an assessment of needs, resources and requirements for screening programmes, Br J Ophthalmol, 2008;92:879-82.

15. Alon T, Hemo I, Itin A, et al., Vascular endothelial growth factor acts as a survival factor for newly formed retinal vessels and has implications for retinopathy of prematurity, Nat Med, 1995:1:1024-8.

16. Ferrara N, Davis-Smyth T, The biology of vascular endothelial growth factor, Endocr Rev, 1997;18:4-25.

17. Shibuya M, Vascular Endothelial Growth Factor (VEGF) and Its Receptor (VEGFR) Signaling in Angiogenesis: A Crucial Target for Anti- and Pro-Angiogenic Therapies, Genes Cancer, 2011;2:1097-105

18. Wuest TR, Carr DJ, VEGF-A expression by HSV-1-infected cells drives corneal lymphangiogenesis, J Exp Med, 2010:207:101-15.

19. Conrady CD, Zheng M, Stone DU, Carr DJ, CD8+T cells suppress viral replication in the cornea but contribute to VEGF-C-induced lymphatic vessel genesis, J Immunol, 2012;189:425-32.

20. Pieh C, Agostini H, Buschbeck C, et al., VEGF-A, VEGFR-1, VEGFR-2 and Tie2 levels in plasma of premature infants: relationship to retinopathy of prematurity, Br J Ophthalmol, 2008;92:689-93.

21. Pierce EA, Foley ED, Smith $L E$, Regulation of vascular endothelial growth factor by oxygen in a model of retinopathy of prematurity, Arch Ophthalmol, 1996;114:1219-28.

22. Morfoisse F, Renaud E, Hantelys F, et al., Role of hypoxia and vascular endothelial growth factors in lymphangiogenesis, $\mathrm{MOl}$ Cell Oncol, 2015;2:e1024821.

23. Forsythe JA, Jiang BH, Iyer NV, et al., Activation of vascular endothelial growth factor gene transcription by hypoxia-inducible factor 1, Mol Cell Biol, 1996:16:4604-13.

24. Hudson CC, Liu M, Chiang GG, et al., Regulation of hypoxiainducible factor 1 alpha expression and function by the mammalian target of rapamycin, Mol Cell Biol, 2002;22:7004-14.

25. Ozaki H, Yu AY, Della N, et al., Hypoxia inducible factor-1alpha is increased in ischemic retina: temporal and spatial correlation with VEGF expression, Invest Ophthalmol Vis Sci, 1999;40:182-9.

26. Wang $\mathrm{H}$, Smith GW, Yang Z, et al., Short hairpin RNA-mediated knockdown of VEGFA in Muller cells reduces intravitreal neovascularization in a rat model of retinopathy of prematurity, Am J Pathol, 2013;183:964-74.

27. Hartnett ME, Martiniuk D, Byfield G, et al., Neutralizing VEGF decreases tortuosity and alters endothelial cell division orientation in arterioles and veins in a rat model of ROP relevance to plus disease, Invest Ophthalmol Vis Sci, 2008;49:3107-14.

28. Zeng G, Taylor SM, McColm JR, et al., Orientation of endothelia cell division is regulated by VEGF signaling during blood vesse formation, Blood, 2007:109:1345-52

29. Smith LE, Pathogenesis of retinopathy of prematurity, Growth Horm IGF Res, 2004;14 Suppl A:S140-4.

30. Hellstrom A, Perruzzi C, Ju M, et al., Low IGF-I suppresses VEGFsurvival signaling in retinal endothelial cells: direct correlation with clinical retinopathy of prematurity, Proc Natl Acad Sci U SA 2001;98:5804-8.

31. Nowak DG, Amin EM, Rennel ES, et al., Regulation of vascular endothelial growth factor (VEGF) splicing from pro-angiogenic to anti-angiogenic isoforms: a novel therapeutic strategy for angiogenesis, J Biol Chem, 2010;285:5532-40.

32. Kennedy SG, Wagner AJ, Conzen SD, et al., The PI 3-kinase/Akt signaling pathway delivers an anti-apoptotic signal, Genes Dev 1997:11:701-13.

33. Hellstrom A, Carlsson B, Niklasson A, et al., IGF-I is critical fo normal vascularization of the human retina, $J$ Clin Endocrinol Metab, 2002;87:3413-6.

34. Lofavist C, Willett KL, Aspegren O, et al., Quantification and localization of the IGF/insulin system expression in retinal blood vessels and neurons during oxygen-induced retinopathy in mice, Invest Ophthalmol Vis Sci, 2009;50:1831-7.

35. Hellstrom A, Engstrom E, Hard AL, et al., Postnatal serum insulinlike growth factor I deficiency is associated with retinopathy of prematurity and other complications of premature birth, Pediatrics, 2003:112:1016-20.

36. Chen J, Smith LE, Retinopathy of prematurity, Angiogenesis, 2007;10:133-40.

37. Peirovifar A, Gharehbaghi MM, Gharabaghi PM, Sadeghi $K$ Vascular endothelial growth factor and insulin-like growt factor-1 in preterm infants with retinopathy of prematurity, Singapore Med J, 2013:54:709-12.

38. An international classification of retinopathy of prematurity, The Committee for the Classification of Retinopathy of Prematurity, Arch Ophthalmol 1984:102:1130-4.

39. An international classification of retinopathy of prematurity. II. The classification of retinal detachment. The International Committee for the Classification of the Late Stages of Retinopathy of Prematurity, Arch Ophthalmol, 1987:105:906-12.

40. Hartnett ME, Penn JS, Mechanisms and management of retinopathy of prematurity, N Eng/ J Med, 2012;367:2515-26.

41. Stahl A, Connor KM, Sapieha P, et al., The mouse retina as an angiogenesis model, Invest Ophthalmol Vis Sci, 2010;51:2813-26.

42. International Committee for the Classification of Retinopathy of Prematurity, The International Classification of Retinopathy of Prematurity revisited, Arch Ophthalmol, 2005;123:991-9.

43. Good WV, Hardy RJ, Dobson V, et al., The incidence and course of retinopathy of prematurity: findings from the early treatment for retinopathy of prematurity study Pediatrics, 2005:116:15-23.

44. Good WV, Early Treatment for Retinopathy of Prematurity Cooperative G. Final results of the Early Treatment for Retinopath of Prematurity (ETROP) randomized trial, Trans Am Ophthalmol Soc, 2004; 102:233-48; discussion 48-50.

45. Mantagos IS, Vanderveen DK, Smith LE, Emerging treatments for retinopathy of prematurity, Semin Ophthalmol, 2009:24:82-6.

46. Palmer EA, Flynn JT, Hardy RJ, et al., Incidence and early course of retinopathy of prematurity. The Cryotherapy for Retinopathy of Prematurity Cooperative Group, Ophthalmology, 1991:98:1628-40.

47. Multicenter trial of cryotherapy for retinopathy of prematurity, One-year outcome--structure and function. Cryotherapy for Retinopathy of Prematurity Cooperative Group, Arch Ophthalmol 1990;108:1408-16.

48. McNamara JA, Tasman W, Brown GC, Federman JL, Laser photocoagulation for stage $3+$ retinopathy of prematurity, Ophthalmology, 1991:98:576-80.

49. Hardy RJ, Palmer EA, Dobson V, et al., Risk analysis of prethreshold retinopathy of prematurity, Arch Ophthalmol, 2003:121:1697-701.

50. Early Treatment For Retinopathy Of Prematurity Cooperative Group Revised indications for the treatment of retinopathy of prematurity. results of the early treatment for retinopathy of prematurity randomized trial, Arch Ophthalmol, 2003:121:1684-94.

51. Cryotherapy for Retinopathy of Prematurity Cooperative Group, Multicenter trial of cryotherapy for retinopathy of prematurity. Snellen visual acuity and structural outcome at $51 / 2$ years after randomization, Arch Ophthalmol, 1996:114:417-24.

52. Siatkowski RM, Good WV, Summers CG, et al., Clinical characteristics of children with severe visual impairment but favorable retinal structural outcomes from the Early Treatmen for Retinopathy of Prematurity (ETROP) study, J AAPOS, 2013;17:129-34

53. Repka MX, Tung B, Good WV et al., Outcome of eyes developing retinal detachment during the Early Treatment for Retinopathy of Prematurity study, Arch Ophthalmol, 2011;129:1175-9.

54. Early Treatment for Retinopathy of Prematurity Cooperative Group, Good WV, Hardy RJ, et al., Final visual acuity results in the early treatment for retinopathy of prematurity study, Arch Ophthalmol, 2010;128:663-71.

55. Maldonado RS, Toth CA, Optical coherence tomography in retinopathy of prematurity: looking beyond the vessels, Clin Perinatol, 2013:40:271-96.

56. Vinekar A, Sivakumar M, Shetty R, et al., A novel technique using spectral-domain optical coherence tomography (Spectralis, SD-OCT+HRA) to image supine non-anaesthetized infants: utility demonstrated in aggressive posterior retinopathy of prematurity, Eye (Lond), 2010;24:379-82

57. Dubis AM, Subramaniam CD, Godara P, et al., Subclinical macular findings in infants screened for retinopathy of prematurity with spectral-domain optical coherence tomography, Ophthalmology, 2013:120:1665-71.

58. Hartnett ME, Vascular endothelial growth factor antagonist therapy for retinopathy of prematurity, Clin Perinatol, 2014;41:925-43.

59. Ells AL, Holmes JM, Astle WF, et al., Telemedicine approach to screening for severe retinopathy of prematurity: a pilot study, Ophthalmology, 2003:110:2113-7.

60. Richter GM, Sun G, Lee TC, et al., Speed of telemedicine vs ophthalmoscopy for retinopathy of prematurity diagnosis, Am J
Ophthalmol, 2009;148:136-42 e2.

61. Lundgren P, Stoltz Sjostrom E, Domellof M, et al., The Specificity of the WINROP Algorithm Can Be Significantly Increased by Reassessment of the WINROP Alarm, Neonatology, 2015;108:152-6.

62. Wu C, Lofqvist C, Smith $L E$, et al., Importance of early postnatal weight gain for normal retinal angiogenesis in very preterm infants: a multicenter study analyzing weight velocity deviations for the prediction of retinopathy of prematurity, Arch Ophthalmol, 2012;130:992-9

63. Cao JH, Wagner BD, Cerda A, et al., Colorado retinopathy of prematurity model: a multi-institutional validation study, J AAPOS, 2016:20:220-5

64. Hutchinson AK, Melia M, Yang MB, et al., Clinical Models and Algorithms for the Prediction of Retinopathy of Prematurity: A Report by the American Academy of Ophthalmology, Ophthalmology, 2016;123:804-16

65. Tah V, Orlans HO, Hyer J, et al., Anti-VEGF Therapy and the Retina: An Update, J Ophthalmol, 2015;2015:627674.

66. Writing Committee for the Diabetic Retinopathy Clinical Research Network, Gross JG, Glassman AR, et al., Panretinal Photocoagulation vs Intravitreous Ranibizumab for Proliferative Diabetic Retinopathy: A Randomized Clinical Trial, JAMA 2015;314:2137-46

67. Avery RL, Pieramici DJ, Rabena MD, et al., Intravitreal bevacizumab (Avastin) for neovascular age-related macular degeneration, Ophthalmology, 2006;11:363-72 e5.

68. Avery RL, Regression of retinal and iris neovascularization after intravitreal bevacizumab (Avastin) treatment, Retina, 2006:26:352-4

69. Comparison of Age-related Macular Degeneration Treatments Trials Research Group, Martin DF, Maguire MG, et al., Ranibizumab and bevacizumab for treatment of neovascular age-related macular degeneration: two-year results, Ophthalmology, 2012;119:1388-98

70. Gragoudas ES, Adamis AP, Cunningham ET, Jr., et al., Pegaptanib for neovascular age-related macular degeneration, N Engl I Med, 2004;351:2805-16.

71. Heier JS, Brown DM, Chong V, et al., Intravitreal aflibercept (VEGF trap-eye) in wet age-related macular degeneration, Ophthalmology, 2012:119:2537-48.

72. Rosenfeld PJ, Brown DM, Heier JS, et al., Ranibizumab for neovascular age-related macular degeneration, N Engl J Med 2006;355:1419-31.

73. Avery RL, Castellarin AA, Steinle NC, et al., Systemic pharmacokinetics following intravitreal injections of ranibizumab, bevacizumab or aflibercept in patients with neovascular AMD, Br J Ophthalmol, 2014:98:1636-41.

74. Geisen P, Peterson $\sqcup$, Martiniuk D, et al., Neutralizing antibody to VEGF reduces intravitreous neovascularization and may not interfere with ongoing intraretinal vascularization in a rat mode of retinopathy of prematurity, Mol Vis, 2008;14:345-57.

75. Castellanos MA, Schwartz S, Garcia-Aguirre G, Quiroz-Mercado $\mathrm{H}$, Short-term outcome after intravitreal ranibizumab injections for the treatment of retinopathy of prematurity, $\mathrm{Br} \perp$ Ophthalmol, 2013;97:816-9.

76. Mintz-Hittner HA, Kennedy KA, Chuang AZ, Group B-RC, Efficacy of intravitreal bevacizumab for stage 3+ retinopathy of prematurity, N Eng/ J Med, 2011;364:603-15.

77. Isaac M, Mireskandari K, Tehrani N, Treatment of type 1 retinopathy of prematurity with bevacizumab versus laser, J AAPOS, 2015:19:140-4.

78. Henaine-Berra A, Garcia-Aguirre G, Quiroz-Mercado H, MartinezCastellanos MA, Retinal fluorescein angiographic changes following intravitreal anti-VEGF therapy, J AAPOS, 2014;18:120-3.

79. Autrata R, Krejcirova I, Senkova K, et al., Intravitreal pegaptanib combined with diode laser therapy for stage $3+$ retinopathy of prematurity in zone I and posterior zone II, Eur J Ophthalmol, 2012;22:687-94

80. Yoon JM, Shin DH, Kim SJ, et al., Outcomes after Laser Versus Combined Laser and Bevacizumab Treatment for Type 1 Retinopathy of Prematurity in Zone I Retina, 2017-37:88-96.

81. Geloneck MM, Chuang AZ, Clark WL, et al., Refractive outcomes following bevacizumab monotherapy compared with conventional laser treatment: a randomized clinical trial, JAMA Ophthalmol, 2014;132:1327-33.

82. Harder BC, Schlichtenbrede FC, von Baltz S, et al., Intravitreal bevacizumab for retinopathy of prematurity: refractive error results, Am J Ophthalmol, 2013:155:1119-24.

83. Hwang CK, Hubbard GB, Hutchinson AK, Lambert SR, Outcomes after Intravitreal Bevacizumab versus Laser Photocoagulation for Retinopathy of Prematurity: A 5-Year Retrospective Analysis, Ophthalmology, 2015;122:1008-15.

84. Chen YH, Chen SN, Lien RI, et al., Refractive errors after the use of bevacizumab for the treatment of retinopathy of prematurity. 2-year outcomes, Eye (Lond), 2014;28:1080-6; quiz 7.

85. Sankar MJ, Sankar J, Mehta M, et al., Anti-vascular endothelia growth factor (VEGF) drugs for treatment of retinopathy of prematurity Cochrane Database Syst Rev, 2016:2:CD009734.

86. Avery RL, Gordon GM, Systemic Safety of Prolonged Monthly Anti-Vascular Endothelial Growth Factor Therapy for Diabetic Macular Edema: A Systematic Review and Meta-analysis, JAMA Ophthalmol, 2016;134:21-9.

87. Virgili G, Parravano M, Menchini F, Evans JR, Anti-vascular endothelial growth factor for diabetic macular oedema, Cochrane Database Syst Rev, 2014:CD007419.

88. Avery RL, Bevacizumab (Avastin) for retinopathy of prematurity: 
wrong dose, wrong drug, or both?, J AAPOS, 2012;16:2-4

89. Saint-Geniez M, Maharaj AS, Walshe TE, et al., Endogenous VEGF is required for visual function: evidence for a survival role on muller cells and photoreceptors, PLOS One, 2008:3:e3554.

90. Jiang $Y$, Wang H, Culp D, et al., Targeting Muller cell-derived VEGF164 to reduce intravitreal neovascularization in the rat model of retinopathy of prematurity, Invest Ophthalmol Vis Sci 2014;55:824-31.

91. Jo DH, Park SW, Cho CS, et al., Intravitreally Injected Anti-VEGF Antibody Reduces Brown Fat in Neonatal Mice, PLOS One, 2015; 10:e0134308.

92. Kong L, Bhatt $A R$, Demny AB, et al., Pharmacokinetics of bevacizumab and its effects on serum VEGF and IGF-1 in infants with retinopathy of prematurity, Invest Ophthalmol Vis Sci, 2015:56:956-61.

93. Wu WC, Lien R, Liao PJ, et al., Serum levels of vascular endothelial growth factor and related factors after intravitreous bevacizumab injection for retinopathy of prematurity, JAMA Ophthalmol, 2015;133:391-7.

94. Zhou $Y$, Jiang $Y$, Bai $Y$, et al., Vascular endothelial growth factor plasma levels before and after treatment of retinopathy of prematurity with ranibizumab, Graefes Arch Clin Exp Ophthalmol, 2016:254:31-6.

95. Hu J, Blair MP, Shapiro MJ, et al., Reactivation of retinopathy of prematurity after bevacizumab injection, Arch Ophthalmol 2012;130:1000-6.

96. Wong RK, Hubschman S, Tsui I, Reactivation of retinopathy of prematurity after ranibizumab treatment, Retina, 2015;35:675-80

97. Morin J, Luu TM, Superstein R, et al., Neurodevelopmental Outcomes Following Bevacizumab Injections for Retinopathy of Prematurity, Pediatrics, 2016;137.

98. Lepore D, Quinn GE, Molle F, et al., Intravitreal bevacizumab versus laser treatment in type 1 retinopathy of prematurity: report on fluorescein angiographic findings, Ophthalmology, 2014;121:2212-9.

99. Ittiara S, Blair MP, Shapiro MJ, Lichtenstein SJ, Exudative retinopathy and detachment: a late reactivation of retinopathy of prematurity after intravitreal bevacizumab, J AAPOS, 2013:17:323-5.

100. Toy BC, Schachar $I H$, Tan GS, Moshfeghi DM, Chronic Vascular Arrest as a Predictor of Bevacizumab Treatment Failure in Retinopathy of Prematurity, Ophthalmology, 2016;123:2166-75.

101. McCloskey M, Wang H, Jiang $Y$, et al., Anti-VEGF antibody leads to later atypical intravitreous neovascularization and activation of angiogenic pathways in a rat model of retinopathy of prematurity, Invest Ophthalmol Vis Sci, 2013:54:2020-6.
102. Chen E, Lin MY, Cox J, Brown DM, Endophthalmitis after intravitreal injection: the importance of viridans streptococci, Retina, 2011;31:1525-33.

103. Reddy MA, Patel HI, Karim SM, et al., Reduced utility of serum IGF1 levels in predicting retinopathy of prematurity reflects maternal ethnicity, Br J Ophthalmol, 2016:100:501-4.

104. Hard AL, Smith LE, Hellstrom A, Nutrition, insulin-like growth factor- 1 and retinopathy of prematurity, Semin Fetal Neonatal Med, 2013; doi:10.1016/j.siny.2013.01.006

105. Ley D, Hansen-Pupp I, Niklasson A, et al., Longitudinal infusion of a complex of insulin-like growth factor-I and IGF-binding protein-3 in five preterm infants: pharmacokinetics and short-term safety Pediatr Res, 2013:73:68-74.

106. Lofqvist C, Niklasson A, Engstrom E, et al. A pharmacokinetic and dosing study of intravenous insulin-like growth factor-I and IGF-binding protein-3 complex to preterm infants, Pediatr Res, 2009;65:574-9

107. Vanhaesebrouck S, Daniels H, Moons L, et al., Oxygen-induced retinopathy in mice: amplification by neonatal IGF-I deficit and attenuation by IGF-I administration, Pediatr Res, 2009:65:307-10.

108. Crawford MA, Costeloe K, Ghebremeskel K, et al., Are deficits of arachidonic and docosahexaenoic acids responsible for the neural and vascular complications of preterm babies?, Am J Clin Nutr, 1997;66(4 Suppl):1032S-41S

109. Kermorvant-Duchemin E, Sennlaub F, Sirinyan M, et al., Transarachidonic acids generated during nitrative stress induce a thrombospondin-1-dependent microvascular degeneration, Nat Med, 2005:11:1339-45.

110. Wang $\mathrm{H}$, Yang Z Jiang Y, Hartnett ME, Endothelial NADPH oxidase 4 mediates vascular endothelial growth factor receptor 2-induced intravitreal neovascularization in a rat model of retinopathy of prematurity, Mol Vis, 2014;20:231-41.

111. Wang $H$, Byfield $G$, Jiang $Y$, et al., VEGF-mediated STAT3 activation inhibits retinal vascularization by down-regulating local erythropoietin expression, Am J Pathol, 2012;180:1243-53.

112. Saito $Y$, Uppal A, Byfield $G$, et al., Activated NAD(P)H oxidase from supplemental oxygen induces neovascularization independent of VEGF in retinopathy of prematurity model, Invest Ophthalmol Vis SCi, 2008:49:1591-8.

113. Saito $Y$, Geisen $P$, Uppal $A$, Hartnett $M E$, Inhibition of $N A D(P) H$ oxidase reduces apoptosis and avascular retina in an anima model of retinopathy of prematurity, Mol Vis, 2007;13:840-53.

114. Christensen RD, Alder SC, Richards SC, et al., A pilot trial testing the feasibility of administering D-penicillamine to extremely low birth weight neonates, J Perinatol, 2006;26:120-4.
115. Ushio-Fukai M, Alexander RW, Reactive oxygen species as mediators of angiogenesis signaling: role of $\mathrm{NAD}(\mathrm{P}) \mathrm{H}$ oxidase, $\mathrm{MO}$ Cell Biochem, 2004;264:85-97.

116. Qureshi MJ, Kumar M, D-Penicillamine for preventing retinopathy of prematurity in preterm infants, Cochrane Database Syst Rev, 2013:CD001073.

117. German OL, Insua MF, Gentili C, et al., Docosahexaenoic acid prevents apoptosis of retina photoreceptors by activating the ERK/MAPK pathway, I Neurochem, 2006;98:1507-20.

118. Rotstein NP, Politi LE, German OL, Girotti R, Protective effect of docosahexaenoic acid on oxidative stress-induced apoptosis of retina photoreceptors, Invest Ophthalmol Vis Sci, 2003;44:2252-9.

119. Giordano $E$, Visioli F, Long-chain omega 3 fatty acids: molecular bases of potential antioxidant actions, Prostaglandins Leukot Essent Fatty Acids, 2014:90:1-4

120. Connor KM, SanGiovanni JP, Lofqvist C, et al., Increased dietary intake of omega-3-polyunsaturated fatty acids reduces pathological retinal angiogenesis, Nat Med, 2007;13:868-73.

121. Sapieha P, Stahl A, Chen J, et al., 5-Lipoxygenase metabolite 4-HDHA is a mediator of the antiangiogenic effect of omega-3 polyunsaturated fatty acids, Sci Trans/ Med, 2011;3:69ra12.

122. Pawlik $D$, Lauterbach $R$, Turyk $E$, Fish-oil fat emulsion supplementation may reduce the risk of severe retinopathy in VLBW infants, Pediatrics, 2011;127:223-8.

123. Pawlik $D$, Lauterbach $R$, Walczak M, et al., Fish-oil fat emulsion supplementation reduces the risk of retinopathy in very low birth weight infants: a prospective, randomized study, JPEN I Parenter Enteral Nutr, 2014;38:711-6.

124. Owens WC, Owens EU, Retrolental fibroplasia in premature infants; studies on the prophylaxis of the disease; the use of alpha tocopheryl acetate, Am J Ophthalmol, 1949:32:1631-7.

125. Brion LP, Bell EF, Raghuveer TS, Vitamin E supplementation for prevention of morbidity and mortality in preterm infants, Cochrane Database Syst Rev, 2003:CD003665.

126. Stevens TP, Finer NN, Carlo WA, et al., Respiratory outcomes of the surfactant positive pressure and oximetry randomized tria (SUPPORT), J Pediatr, 2014:165:240-9 e4.

127. Khadawardi E, Al Hazzani F, Oxygen Saturation and Outcomes in Preterm Infants The BOOST II United Kingdom, Australia, and New Zealand Collaborative Groups, J Clin Neonatol, 2013;2:73-5.

128. Schmidt B, Whyte RK, Asztalos EV, et al., Effects of targeting higher vs lower arterial oxygen saturations on death or disability in extremely preterm infants: a randomized clinical trial, JAMA, 2013;309:2111-20.

129. Laser ROP Study Group, Laser therapy for retinopathy of prematurity, Arch Ophthalmol, 1994:112:154-6. 